\title{
Basal metabolic rate and energy expenditure of pregnant Nigerian women
}

\author{
BY A. H. COLE', P. A. IBEZIAK ${ }^{2}$ AND E. A. BAMGBOYE \\ ${ }^{1}$ Department of Human Nutrition, ${ }^{2}$ Department of Obstetrics and Gynaecology, ${ }^{3}$ Department of \\ Preventive and Social Medicine, College of Medicine, University of Ibadan, Ibadan, Nigeria
}

(Received 21 February 1989 - Accepted 14 June 1989)

\begin{abstract}
The purpose of the present study was to compare basal metabolic rates (BMR) of pregnant Nigerian women from rural and urban areas with values from similar studies in other Third World countries. We also investigated possible changes in BMR during the course of pregnancy. An open-circuit indirect calorimeter was used to measure BMR and energy expenditure (EE) during sedentary activity in fortyone pregnant Nigerian women. The results showed marked variability in BMR among individuals. A correlation analysis between BMR and other biological and physical characteristics revealed bodyweight and gestation as the only variables related to BMR and oxygen consumption.

The study revealed no significant difference between BMR and EE of sedentary activity in the subjects. The wide variability may have been due to the nutritional status of the subjects studied, who were drawn largely from the lower socioeconomic groups of Nigerian society. The present study shows that socioeconomic status and nutritional interventions should be taken into account when framing recommendations for maternal nutrition during pregnancy.
\end{abstract}

Basal metabolic rate: Energy expenditure: Pregnancy

Famine and poverty contribute significantly to the low energy and poor dietary intakes of many people in the Third World. As Waterlow (1987) has aptly remarked, "the underlying cause of malnutrition in the Third World is poverty (which) can only be eliminated by political and economic changes'. Nigeria is a Third World country, and poverty and hunger are serious problems facing many people in both rural and urban areas.

Pregnancy is usually accompanied by, among other changes, a considerable increase of metabolically active tissues. Other important physiological changes include: the growth of the fetus and the placenta, an enlargement and hypertrophy of the organs of reproduction and increases in the volumes of circulating blood and other body fluids. Since the present study is concerned specifically with basal metabolic rate (BMR), and energy expenditure (EE) of pregnant Nigerian women, it should provide information useful for predicting and prescribing the energy and nutritional requirements of such women.

This is, to the best of our knowledge, the first study dealing with the BMR and energy cost of activity in pregnant Nigerian women, although Cole \& Ogungbe (1987) investigated the food intake and EE of female Nigerian students. Indeed, there are very few studies on the BMR of pregnant women in Africa as a whole, or the Third World generally. The few reported studies have indicated that BMR values for African women are lower than those for their counterparts in the Western world (Lawrence et al. 1986).

Lawrence et al. (1984), in their study of pregnant women in The Gambia, produced some convincing evidence for metabolic adaptation when they observed a fall in their subjects' BMRs which they suggested may have been due to effective metabolic adaptation to increased energy demands. Maletnlema \& Bavu (1974) had earlier studied the nutritional status of seventy pregnant Tanzanian women from Kisirawe, using weighing and recall methods to estimate the dietary intakes of their subjects. Working with Indian women, De 
\& Nagchaudhuri (1975) reported an increased mean BMR in 100 pregnant women. The increase was of the order of 5-6\% during the third trimester. Dakshayani \& Ramanamurity (1964) had earlier reported a similar increase between the second and third trimester in pregnant Indian women.

The weight gain during pregnancy in developed countries is about $12.5 \mathrm{~kg}$, and median infant birth weight is $3.3 \mathrm{~kg}$ (coefficient of variation 15\%) (Hytten, 1980). For a typical pregnancy, the average energy cost has been calculated to be about $335 \mathrm{MJ}$ ( $80000 \mathrm{kcal})$ over the 9-month period. This is distributed, according to the report of the Food and Agriculture Organization/World Health Organization (1973), as an extra $630 \mathrm{~kJ}$ (150 $\mathrm{kcal}) / \mathrm{d}$ during the first trimester and $1465 \mathrm{~kJ}(350 \mathrm{kcal}) / \mathrm{d}$ during the second and third trimesters. Banerjee et al. (1971) found that in pregnant Chinese, Malay and Indian women the BMR was $27 \%$ higher, but body-weight only $13 \%$ higher, than in non-pregnant women.

\section{MATERIALS AND METHODS}

The forty-one pregnant women (age range 18-40 years) who took part in the study were randomly selected from among those registered at the antenatal clinic of the University College Hospital (UCH), Ibadan. They were of low and medium socioeconomic status from the rural and urban areas of Ibadan, Oyo State of Nigeria, and were engaged in subsistence farming, some small-scale trading or certain semi-skilled jobs. Efforts were made to select pregnant women in the early and later stages of pregnancy, and none had ever smoked.

The Ethical Committee of the College of Medicine, University of Ibadan had approved the project, and the informed consent of the participants was sought and obtained before the study began.

At $1 \mathrm{~d}$ before the measurements, the subjects were admitted to the antenatal ward of the hospital (UCH). This was to enable us to comply strictly with the standardized requirements for measuring BMR: that subjects be under standardized resting conditions, that they be bodily and mentally at rest, that measurements be taken $12-14 \mathrm{~h}$ after the subjects' last meal and that measurements take place in a thermoneutral environment. The BMR was measured between 06.30 and 07.30 hours, more than $12 \mathrm{~h}$ after the subjects had had their last meal. They had also had at least $8 \mathrm{~h}$ sleep. EE was measured later, with the women sedentary.

\section{Measurement of $B M R$}

Indirect calorimetry was used to measure the BMR of the forty-one subjects.

Respiration-gas meters of the Max Planck Institute for Work Physiology, Dortmund, developed in Germany, modified by Müller \& Franz (1952) and manufactured by Gesellschaft für Gerätebau (Dortmund, West Germany), combined with face masks, were used to measure the volume of expired air $\left(\dot{V}_{\mathrm{E}}\right)$. The respirometer was calibrated as described by Cole (1976). The face masks were in three different sizes. They were manufactured by Volkseigener Betrieb Kombinant Medizin und Labor Technik, Leipzig, GDR. To suit our physiological purpose, the face masks were modified ir the workshop of the Central Institute of Nutrition, Academy of Sciences of GDR, Potsdam-Rehbrücke.

Each subject breathed through a face mask via a corrugated tube to the respirometer and from thence to an inflatable rubber bag; this was placed inside a plastic sack which was filled with expired air to prevent changes in the gas content of the gas bladder (Rahaman \& Durnin, 1964) before analysis. $\dot{V}_{\mathrm{E}}$ and temperature (using the thermometer in the respirometer) of expired air were recorded. Air pressure was measured using a barometer. 


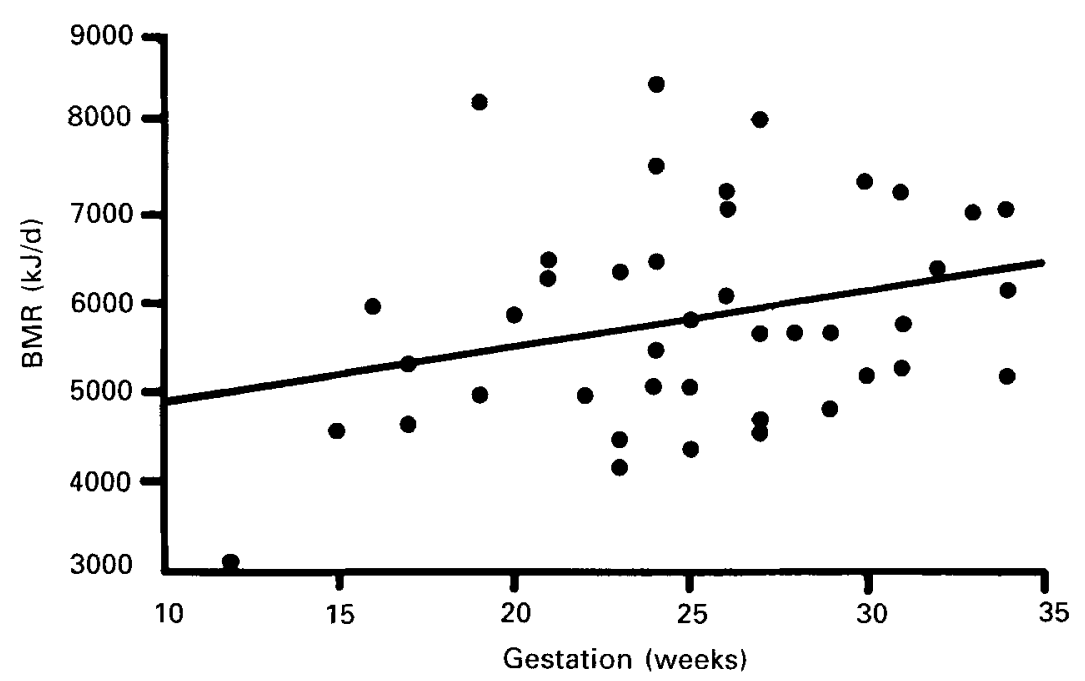

Fig. 1. Scatter diagram of relation between basal metabolic rate (BMR, kJ/d) and gestation (weeks). $(Y=4236+64.8 X ; r 0 \cdot 28, P<0 \cdot 05$.)

The measured gas volume was corrected to standard temperature and pressure and the volume of inspired air was derived from $\dot{V}_{\mathrm{E}}$ and the gas concentrations. The oxygen and carbon dioxide concentrations of the mixed expired gas sampled by the inflatable bag through the respirometer were measured using a polargraphic $\mathrm{O}_{2}$-analyser (Medical Analyser OM-11; Beckmann) and an infrared absorption $\mathrm{CO}_{2}$ analyser (Medical Analyser LB-2; Beckmann). Both analysers were calibrated regularly with a certified gas mixture of $\mathrm{O}_{2}, \mathrm{CO}_{2}$ and nitrogen (19:9:4·1:76, by vol.) (BOC, London).

\section{Measurement of EE while sitting quietly}

EE was measured following the same procedure as in the measurement of BMR. This time, however, the subjects were in a sedentary position, had had breakfast and measurements took place between $08 \cdot 30$ and $09 \cdot 30$ hours.

\section{RESULTS}

$B M R$

The mean values for indices of the biological and physical characteristics of the forty-one pregnant women in the study are presented in Table 1 (detailed values in the Appendix). There was a wide variability in BMR among individual subjects at all stages of pregnancy. For example, the highest BMR of $8345 \mathrm{~kJ} / \mathrm{d}$ was recorded for a woman in her 19th week of gestation, while the lowest BMR of $3121 \mathrm{~kJ} / \mathrm{d}$ was from a subject in her 12 th week of pregnancy.

Analysis of all the variables showed that only body-weight and gestation were significantly correlated with BMR $(P<0.05)$; Pearson correlation coefficients were 0.56 and 0.28 respectively. Further analysis of the values showed that the linear equations BMR = $1361+73 \times$ body-weight, and $\mathrm{BMR}=4236+65 \times$ gestation, can adequately describe the relations between BMR and body-weight and BMR and gestation respectively. When BMR was corrected for body-weight, its relation with body-weight was no longer significant $(P>0.05)$. The scatter diagram of BMR in relation to gestation is shown in Fig. 1. 


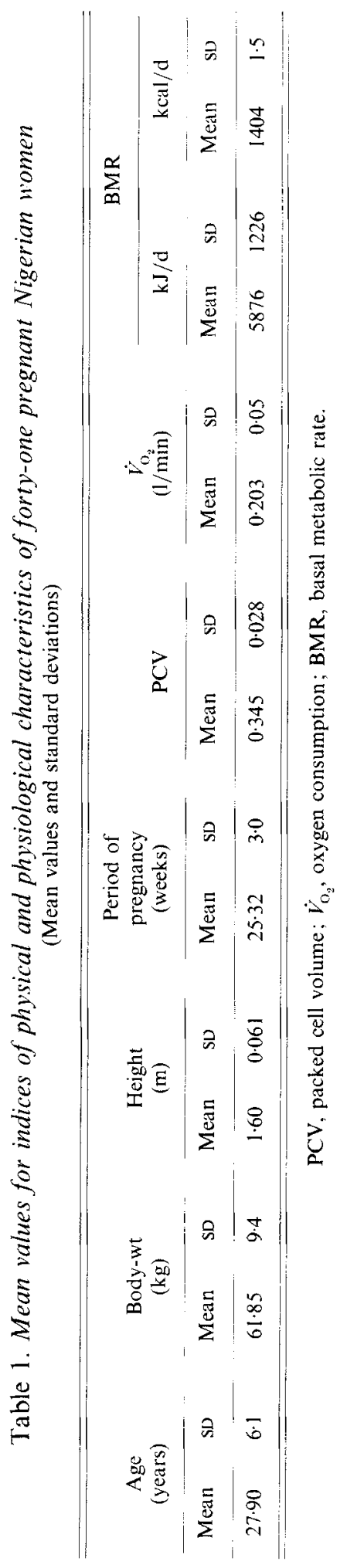




\section{$E E$}

There was no significant difference between BMR and EE in the sedentary condition $(P>$ 0.05 ). The forty-one subjects had a mean $\mathrm{O}_{2}$ consumption of 0.220 (SD 0.81 ) $1 / \mathrm{min}$, respiratory quotient 0.81 (SD 0.11 ) and mean EE of 4.44 (SD 1.29) $\mathrm{kJ} / \mathrm{min}(0.95$ (SD 0.31$)$ $\mathrm{kcal} / \mathrm{min}$ ).

\section{DISCUSSION}

The differing socioeconomic status of the subjects (see p. 632) and the varying levels of their normal activities are plausible explanations for the wide variability in BMR. It is quite reasonable to expect EE to bear some relation to nutritional status and to the degree (heavy or light) of the physical activity of the subjects. This seems to have been the case in the present study, resulting in the wide variability already noted in the BMR. Another possible reason could be the method used for the measurement of BMR. However, in the present study, in which the standardized method was strictly followed, variability would not seem to be attributable to methodology.

It can also be argued that differences in the proportion of lean body mass among individuals with different levels of energy and dietary intake, coupled with the fact that small differences do exist in the mass of metabolically active organs, could have contributed to the wide variability observed. Ferro-Luzzi (1986), for example, made a similar suggestion. Since the subjects in the study were obviously of ample body size, it is difficult to assess to what extent variability in BMR was due to differences in the proportion of lean body mass or metabolically active mass. We did not determine the body composition of the subjects in the present study.

Despite the wide variability in BMR found in the present study, our results are comparable with information on BMR obtained for women in The Gambia, India, China, Thailand and the Philippines. Basal EE of the subjects in this study does not differ significantly from values reported by Lawrence et al. (1984), Khan \& Belavady (1973), De \& Nagchaudhuri (1975), Banerjee et al. (1971), Dakshayani \& Ramanamurity (1964), Durnin (1982) and Blackburn \& Calloway $(1976,1985)$. However, our values are slightly higher than those reported by Banerjee et al. (1971), Khan \& Belavady (1973), De \& Nagchaudhuri (1975) and Lawrence et al. (1984).

In conclusion, the present paper presents useful information for policy makers and nutrition scientists in Nigeria. The wide variability among individuals at all stages of pregnancy might be due to the nutritional status of the subjects studied, which are largely from a low socioeconomic group. Durnin (1982) indicated that women can have normal pregnancies and breast-feed their children even though their nutrient intakes are far below recommended levels. If we accept Durnin's (1982) suggestion, there is a strong possibility that because of cultural and physiological adaptations the nutritional requirements of some pregnant and lactating women may not be much greater than those of non-pregnant women. We should like to reiterate that previously there was no information on BMR and EE of Nigerian women at various stages of pregnancy. The published information currently available from other African countries, such as The Gambia, is inadequate and does not constitute an adequate basis to enable the Nigerian nutritionist to advise the appropriate authorities in prescribing adequate dietary and energy allowances for pregnant women in Nigeria.

It is, therefore, recommended that in order to generate this much-needed information, the present study should continue on a longitudinal basis to include such topics as: food intake, EE of activity, body composition (anthropometry) and multiple measurements of the subjects throughout pregnancy. 
The study was fully supported through a grant to A.H.C. by the Nestlé Nutrition Research Grant Programme Committee, London, under the former Chairmanship of Professor J. C. Waterlow, CMC, FRCP, FRS.

The authors wish to express their deepest gratitude to the forty-one pregnant Nigerian women for their participation in the study. The authors thank the matron, the nursing sisters W4, SW4 and SE4, University College Hospital (UCH), Ibadan for their careful observation and assistance during the overnight rest of the subjects in their respective wards. The technical assistance given by Mr M. O. A. Akinyemi, of the Department of Anaesthesia, College of Medicine, University of Ibadan, is also gratefully acknowledged. Finally, thanks go to Miss Joy N. Onyemaobi and Mr Babalola Edegbai, former field officers in the Department of Human Nutrition, College of Medicine, University of Ibadan, Ibadan, Nigeria.

\section{REFERENCES}

Banerjee, B., Khawa, K. S. \& Saha, N. (1971). A comparative study of energy expenditure in some common daily activities on non-pregnant and pregnant Chinese, Malay and Indian women. Journal of Obstetrics and Gynaecology of the British Commonwealth 78, 113-116.

Blackburn, N. W. \& Calloway, D. H. (1976). Basal metabolic rate and work energy expenditure of mature pregnant women. Journal of the American Dictetic Association 69, 24-28.

Blackburn, N. W. \& Calloway, D. H. (1985). Heart rate and energy expenditure of pregnant and lactating women. American Journal of Clinical Nutrition 42, 1161 1169.

Cole, A. H. (1976). Untersuchungen zum Energieumsatz bei normalgewichtigen und adipösen Persönen als Beitrag zum problem Ernährung und Leistung und als theoretisch-methodische Voraussetzung entsprechender Untersuchungen unter tropischen Bedingungen. Inaugural Dissertation, Akademie der Wissenschaften der DDR, Berlin.

Cole, A. H. \& Ogungbe, R. F. (1987). Food intake and energy expenditure of Nigerian female students. British Journal of Nutrition 57, 309-318.

Dakshayani, R. \& Ramanamurity, P. S. V. (1964). Basal metabolism and creatinine excretion in different physiological groups. Indian Journal of Medical Research 52, $1159-1164$.

De, A. K. \& Nagchaudhuri, J. (1975). Studies on basal metabolic rate - pregnant and lactating women in Varanasi. Indian Journal of Medical Research 63, 613-616.

Durnin, J. V. G. A. (1982). Energy requirements of pregnant and lactating women. Nestle Foundation Annual Report, pp. 13-22, 47-62. Vevey: Nestlé.

Ferro-Luzzi, A. (1986). Range of variation in energy expenditure and scope for regulation. In Proceedings of the XIhh Inemational Congress of Nutrition, Brighton, pp. 393-399 [T. G. Taylor and N. K. Jenkins, editors]. London: John Libbey.

Food and Agriculture Organization/World Health Organization (1973). Energy and Protein Requirements. Technical Report Series no. 522 Geneva: WHO.

Hytten, F. F. (1980). In Clinical Physiology in Obstetrics, pp. 193-233 [F. F. Hytten and G. Chamberlain, cditors]. Oxford: Blackwell Scientific Publication.

Khan, L. \& Belevady, B. (1973). Basal metabolism in pregnant and nursing women and children. Indian Journal of Medical Research 61, 1853-1860.

Lawrence, M. L., Lawrence, F., Coward, W. A., Cole, T. J. \& Whitehead, R. G. (1986). Energy expenditure and energy balance during pregnancy and lactation in The Gambia. Nestle Foundation Annual Report, pp. 77-103. Vevey: Nestlé.

Lawrence, M. L., Lawrence, F., Lamb, W. H. \& Whitehead, R. G. (1984). Maintenance energy cost of pregnancy in rural Gambian women and influence of dietary status, Lancet ii, 363-365.

Maletnlema, T. W. \& Bavu, J. L. (1974). Nutritional studies in pregnancy. East African Medical Journal 51, 515-528.

Müller, E. A. \& Franz, H. (1952). Energie verbrauchsmessungen bei beruflicher mit einer Verbesserten Respirations-Gasuhr. Arbeitsphysiologie 14, 499.

Rahaman, N. M. \& Durnin, J. V. G. A. (1964). Changes in concentration of gases in the rubber bladders of MaxPlanck respirometers. Journal of Applied Physiology 19, 1188-1191.

Waterlow, J. W. (1987). Discussion on famine, introductory remarks. Proceedings of the Nutrition Socicty 46, 259261 
Appendix. Physical and physiological characteristics and basal metabolic rate (BMR) of forty-one pregnant Nigerian women at various gestational stages

\begin{tabular}{|c|c|c|c|c|c|c|c|}
\hline $\begin{array}{c}\text { Subject } \\
\text { no. }\end{array}$ & $\begin{array}{l}\text { Period of } \\
\text { gestation } \\
\text { (weeks) }\end{array}$ & $\begin{array}{c}\text { Age } \\
\text { (years) }\end{array}$ & $\begin{array}{c}\text { Body-wt } \\
(\mathrm{kg})\end{array}$ & $\begin{array}{c}\text { Height } \\
\text { (m) }\end{array}$ & $\mathrm{PCV}$ & $\begin{array}{c}\dot{V}_{\mathrm{o}_{2}} \\
(1 / \mathrm{min})\end{array}$ & $\begin{array}{c}\text { BMR } \\
(\mathrm{kJ} / \mathrm{d})\end{array}$ \\
\hline 1 & 12 & 20 & 54 & 1.63 & $0 \cdot 36$ & $0 \cdot 107$ & 3121 \\
\hline 2 & 15 & 35 & 75 & 1.61 & $0 \cdot 30$ & 0.157 & 4589 \\
\hline 3 & 16 & 27 & 74 & $1 \cdot 74$ & 0.35 & $0 \cdot 24$ I & 6008 \\
\hline 4 & 17 & 35 & 69 & 1.61 & 0.37 & 0.225 & 4644 \\
\hline 5 & 19 & 30 & 67 & 1.69 & 0.37 & 0.285 & 8345 \\
\hline 6 & 19 & 32 & 51 & 1.52 & $0 \cdot 36$ & $0 \cdot 178$ & 5019 \\
\hline 7 & 20 & 22 & 47 & 1.59 & 0.35 & 0.206 & 5871 \\
\hline 8 & 21 & 20 & 58 & 1.65 & $0 \cdot 30$ & 0.222 & 6302 \\
\hline 9 & 21 & 40 & 78 & 1.63 & 0.26 & 0.231 & 6498 \\
\hline 10 & 22 & 25 & 46 & 1.52 & 0.33 & $0 \cdot 170$ & 5021 \\
\hline 11 & 23 & 18 & 58 & 1.65 & 0.35 & 0.226 & 6387 \\
\hline 12 & 23 & 18 & 53 & 1.57 & 0.28 & 0.145 & 4193 \\
\hline 13 & 23 & 25 & 56 & $1 \cdot 60$ & 0.35 & $0 \cdot 148$ & 4406 \\
\hline 14 & 24 & 37 & 59 & 1.49 & 0.36 & $0 \cdot 186$ & 5133 \\
\hline 15 & 24 & 35 & 70 & 1.67 & $0 \cdot 36$ & 0.257 & 7573 \\
\hline 16 & 24 & 37 & 89 & 1.63 & 0.37 & 0.297 & 8519 \\
\hline 17 & 24 & 21 & 65 & 1.56 & $0 \cdot 34$ & $0 \cdot 189$ & 5465 \\
\hline 18 & 24 & 35 & 57 & 1.49 & 0.32 & 0.232 & 6483 \\
\hline 19 & 25 & 36 & 56 & 1.61 & 0.35 & $0 \cdot 156$ & 4368 \\
\hline 20 & 25 & 21 & 51 & $1 \cdot 55$ & 0.29 & 0.170 & 5063 \\
\hline 21 & 25 & 28 & 66 & 1.66 & 0.34 & $0 \cdot 183$ & 5266 \\
\hline 22 & 26 & 35 & 70 & 1.55 & 0.36 & 0.259 & 7255 \\
\hline 23 & 26 & 21 & 65 & 1.57 & 0.35 & $0 \cdot 106$ & $712 !$ \\
\hline 24 & 26 & 30 & 65 & 1.66 & 0.35 & 0.213 & 6067 \\
\hline 25 & 27 & 25 & 70 & 1.55 & 0.37 & 0.294 & 5116 \\
\hline 26 & 27 & 31 & 71 & 1.65 & 0.36 & 0.201 & 5669 \\
\hline 27 & 27 & 34 & 55 & $1 \cdot 54$ & 0.37 & 0.451 & 4644 \\
\hline 28 & 27 & 29 & 52 & $1 \cdot 55$ & 0.35 & 0.151 & 4598 \\
\hline 29 & 28 & 30 & 57 & 1.57 & 0.35 & 0.192 & 5682 \\
\hline 30 & 29 & 21 & 55 & 1.64 & 0.37 & $0 \cdot 167$ & 4892 \\
\hline 31 & 29 & 30 & 56 & 1.57 & 0.35 & $0 \cdot 192$ & 5682 \\
\hline 32 & 30 & 30 & 79 & 1.60 & $0 \cdot 38$ & 0.252 & 7392 \\
\hline 33 & 30 & 26 & 62 & $1 \cdot 49$ & 0.36 & 0.173 & 5222 \\
\hline 34 & 31 & 30 & 55 & $1 \cdot 50$ & 0.30 & $0 \cdot 184$ & 5289 \\
\hline 35 & 31 & 26 & 63 & 1.66 & 0.37 & $0 \cdot 203$ & 5832 \\
\hline 36 & 31 & 28 & 59 & 1.62 & 0.34 & 0.255 & 7326 \\
\hline 37 & 32 & 18 & 68 & 1.67 & $0 \cdot 33$ & 0.227 & 6362 \\
\hline 38 & 33 & 31 & 55 & 1.54 & 0.39 & 0.249 & 7049 \\
\hline 39 & 34 & 24 & 63 & 1.65 & 0.36 & 0.209 & 6158 \\
\hline 40 & 34 & 22 & 52 & 1.57 & 0.32 & 0.176 & 5196 \\
\hline 41 & 34 & 26 & 65 & 1.65 & 0.35 & 0.254 & 7121 \\
\hline Mean & $25 \cdot 32$ & $27 \cdot 9$ & 61.85 & 1.66 & $0 \cdot 35$ & 0.203 & 5876 \\
\hline SD & $5 \cdot 36$ & $6 \cdot 1$ & $9 \cdot 35$ & 608 & 3.0 & 0.05 & 1226 \\
\hline
\end{tabular}

PCV, packed cell volume; $\dot{V}_{\mathrm{U}_{\mathrm{z}}}$, oxygen consumption; BMR, basal metabolic rate. 